\title{
Action of Chlorpromazine
}

\section{MITOCHONDRIAL ADENOSINE TRIPHOSPHATASE AND THE ADENOSINE TRIPHOSPHATE-ADENOSINE DIPHOSPHATE EXCHANGE*}

\author{
By M. J. R. DAWKINS, $\dagger$ J. D. JUDAH $\ddagger$ AND K. R. REES \\ Departments of Morbid Anatomy and Chemical Pathology, University College Hospital \\ Medical School, London, W.C. 1
}

(Received 11 January 1960)

We have shown that the phenothiazine tranquillizer chlorpromazine [2-chlorophenothiazine10-(3-dimethylaminopropyl)] inhibits cytochrome oxidase (Dawkins, Judah \& Rees, 1959a) and reduced diphosphopyridine nucleotide-cytochrome $c$ reductase (Dawkins, Judah \& Rees, 1959b). In the latter case inhibition was found in phosphorylating systems only, and it was suggested that chlorpromazine might be acting on one of the coupled phosphorylation reactions.

There is much evidence to suggest that magnesium-activated adenosine triphosphatase of mitochondria is a sequence of enzyme-catalysed reactions in which the terminal steps of oxidative phosphorylation are reversed. This may occur in preparations no longer able to couple electron transport with the phosphorylation of adenosine diphosphate (see Siekevitz, Löw, Ernster \& Lindberg, 1958). We have therefore investigated the action of chlorpromazine on the magnesiumactivated adenosine triphosphatase of mitochondria and extracts prepared from them in various states of structural disintegration.

Recently Lehninger (1958) has suggested that the terminal reaction of oxidative phosphorylation is the adenosine triphosphate-adenosine diphosphate exchange. The enzyme catalysing this reaction can be isolated from mitochondria in soluble form, and is not sensitive to 2:4-dinitrophenol. We have therefore examined the effect of chlorpromazine, and other agents such as azide and guanidine, on the adenosine triphosphate-adenosine diphosphate exchange since this reaction is almost certainly the initial step in the breakdown of adenosine triphosphate.

The results obtained in this paper on the effect of chlorpromazine on mitochondrial adenosine triphosphatase are in agreement with the findings of Löw (1959), published during the course of this work.

* Part 2: Dawkins, Judah \& Rees (1959b).

$\dagger$ This work was done during tenure of the Stothert research fellowship of the Royal Society.

¥ Present address: Wistar Institute, Philadelphia, 4, Pa., U.S.A.

\section{METHODS}

Animals. Albino rats of the Wistar strain, weight 150 $250 \mathrm{~g}$., fed with the MRC $41 \mathrm{~B}$ diet without restriction, were used.

Mitochondria. These were isolated from rat liver in $0.25 \mathrm{M}-$ sucrose by the method of Schneider (1948). They were washed in $0.25 \mathrm{M}$-sucrose and suspended in $0.25 \mathrm{M}$-sucrose or water.

Microsomes. These were isolated from liver homogenates by centrifuging the mitochondria at $8000 \mathrm{~g}$ for $15 \mathrm{~min}$., followed by centrifuging at $105000 \mathrm{~g}$ for $60 \mathrm{~min}$. in the Spinco model L preparative ultracentrifuge. The pellet was then suspended in $0 \cdot 25 \mathrm{M}$-sucrose.

Submitochondrial preparations. Three preparations were used. (1) Mitochondria were fragmented in a Waring Blendor, and small particles isolated by differential centrifuging as described by Kielly \& Kielly (1953). (2) Mitochondria derived from $10 \mathrm{~g}$. of liver were suspended in icecold $3 \mathrm{~mm}-\mathrm{K}_{2} \mathrm{HPO}_{4}$, and then subjected to sonic oscillation for $10 \mathrm{~min}$. in the Mullard-MSE sonic oscillator (Measuring and Scientific Equipment Ltd., London) tuned for maximum performance $\left(20 \mathrm{kcyc} / \mathrm{sec}\right.$.) with the $\frac{3}{4}$ in.-diameter probe. The particles were kept ice-cold during the process. The suspension was then centrifuged in a refrigerated centrifuge at $20000 \mathrm{~g}$ for $15 \mathrm{~min}$. and the small residue was discarded. The turbid supernatant fluid was centrifuged at $105000 \mathrm{~g}$ for $30 \mathrm{~min}$. in the Spinco model $\mathrm{L}$ preparative ultracentrifuge. Two fractions were obtained, a gelatinous red-brown precipitate, which was suspended in water (sonic-residue preparation, SR), and the supernatant (sonic-supernatant preparation, SS). (3) The particles obtained from $18 \mathrm{~g}$. of liver after sonic oscillation (SR preparation) were suspended in water and treated with 4 vol. of ice-cold acetone added cautiously with stirring. The flocculent precipitate was washed repeatedly on a small sintered-glass funnel with ice-cold acetone, and then dried rapidly in vacuo in a desiccator containing liquid paraffin and $\mathrm{KOH}$. The yield was $187 \mathrm{mg}$. of a pink powder. The powder was suspended in ice-cold water $(10 \mathrm{mg} . / \mathrm{ml}$.), and triturated well and the suspension was centrifuged at $3000 \mathrm{~g}$ for $10 \mathrm{~min}$. The opalescent supernatant fluid was used immediately.

Reagents. Adenosine triphosphate (ATP) was the product of the Sigma Chemical Co., St Louis, Mo., U.S.A. 32P was obtained from The Radiochemical Centre, Amersham, Bucks., and was purified as described by Kennedy (1953). [ [2P]Adenosine diphosphate (ADP) was prepared as described by Cooper \& Lehninger (1957). Chlorpromazine was a gift from May and Baker Ltd., Dagenham, 


\section{Table 1. Effect of chlorpromazine and 2:4-dinitrophenol on adenosine triphosphatase} of fresh mitochondria in $0.25 \mathrm{M}-$ sucrose

Components of the system were ATP, $5 \mathrm{~mm} ; \mathrm{MgSO}_{4}, 10 \mathrm{~mm} ; \mathrm{KCl}, 37 \cdot 5 \mathrm{~mm}_{;}$2-amino-2-hydroxymethylpropane1:3-diol-HCl buffer, pH 7.2, $50 \mathrm{~mm}$. Mitochondria were added in $0.2 \mathrm{ml}$. of $0.25 \mathrm{M}$-sucrose, and were equivalent to $0.7 \mathrm{mg}$. of mitochondrial N. Final volume was $2 \mathrm{ml}$.; temperature was $25^{\circ}$; time of incubation was 20 min.

\begin{tabular}{|c|c|c|c|c|}
\hline & Control & $\begin{array}{l}\text { Chlorpromazine } \\
(0 \cdot 2 \mathrm{~mm})\end{array}$ & $\begin{array}{l}\text { 2:4-Dinitrophenol } \\
(0.03 \mathrm{~mm})\end{array}$ & $\begin{array}{c}(0.2 \mathrm{~mm})+ \\
\text { 2:4-dinitrophenol } \\
(0.03 \mathrm{~mm})\end{array}$ \\
\hline Inorganic $P$ liberated ( $\mu$ moles) & $0 \cdot 87$ & $\mathbf{1} \cdot \mathbf{6}$ & $3 \cdot 6$ & 1.9 \\
\hline
\end{tabular}

Essex. Hexokinase was prepared from yeast as described previously (Dawkins et al. $1959 a$ ).

Measurement of breakdown of adenosine triphosphate. This was studied in the following system: ATP $5 \mathrm{~mm} ; \mathrm{MgSO}_{4}$ $10 \mathrm{~mm}$; $\mathrm{KCl} \mathrm{37.5} \mathrm{mM;} \mathrm{2-amino-2-hydroxymethylpropane-}$ 1:3-diol-HCl buffer, pH 7.2, $50 \mathrm{~mm} ; 0.2 \mathrm{ml}$. of enzyme and water to $2 \mathrm{ml}$. The temperature was $25^{\circ}$ and the time of incubation was as indicated in the tables. The inorganic phosphate liberated was determined by the method of Fiske \& Subbarow (1925).

Measurement of adenosine triphosphate-adenosine diphosphate-exchange rate. This was measured in the following system: ATP $5 \mathrm{~mm}$; [ $\left.{ }^{32} \mathrm{P}\right]$ ADP $1.25 \mathrm{~mm}$, with an activity of 2800 counts/min. corrected for background and residual amounts of [ $\left.{ }^{32} \mathrm{P}\right] \mathrm{ATP} ; 2$-amino-2-hydroxymethylpropane1:3-diol-HCl buffer, $\mathrm{pH} \mathrm{7 \cdot 2,50} \mathrm{mM;} \mathrm{enzyme} \mathrm{in} 0 \cdot 2 \mathrm{ml}$. of water. The final volume was $2 \mathrm{ml}$., temp. $20^{\circ}$ and the incubation time $30 \mathrm{~min}$. The reaction was ended by the addition of $1 \mathrm{ml}$. of $10 \%(\mathrm{v} / \mathrm{v})$ perchloric acid, the precipitated protein was centrifuged off and the supernatant fluid neutralized with $\mathrm{KOH}$ and made to volume. It was then chilled and the $\mathrm{KClO}_{4}$ centrifuged off. A sample was analysed for nucleotides by ascending chromatography on Whatman no. 1 filter paper, with solvent-system 3 as described in Pabst Laboratories Circular OR-10 (Pabst Laboratories, 1037 W. McKinley Avenue, Wisconsin, U.S.A.). This consists of $1 \mathrm{l}$. of $0 \cdot 1 \mathrm{M}-\mathrm{Na}_{2} \mathrm{HPO}_{4}$, adjusted to pH 6.8 with $\mathrm{HCl}$, to which is added $20 \mathrm{ml}$. of propanol and $600 \mathrm{~g}$. of $\left(\mathrm{NH}_{4}\right)_{2} \mathrm{SO}_{4}$. The chromatograms were developed for $20 \mathrm{hr}$. at $20^{\circ}$ in large jars, and air-dried and the spots outlined under u.v. light and cut out. Radioactivity was determined by elution of the paper with water and counting the solution in a liquid counter (20th Century Electronics Ltd.; thin-walled B6) or by placing the spots under a halogen-filled end-window counter. Measurements are corrected for isotope decay, background and dead tine of the instrument. The counting equipment was of conventional design. All results are representative of at least three similar experiments.

\section{RESULTS}

Adenosine triphosphatase of mitochondria. The rate of ATP breakdown in the presence of $\mathrm{Mg}^{2+}$ ions by fresh mitochondria in $0.25 \mathrm{M}$-sucrose is known to be small (Lardy \& Wellman, 1953). When chlorpromazine at a concentration of $0.2 \mathrm{~mm}$ was tested in this system it was found that the rate of breakdown was nearly doubled. 2:4-Dinitrophenol $(0.03 \mathrm{~mm})$ accelerated the rate fourfold, but the
Table 2. Effect of chlorpromazine and 2:4dinitrophenol on water-treated mitochondria

The components of the system were as described in Table 1. Mitochondria were added in $0.2 \mathrm{ml}$. of water, equivalent to $0.12 \mathrm{mg}$. of mitochondrial $\mathrm{N}$. The time of incubation was $10 \mathrm{~min}$. Before use they had been suspended in water for $45 \mathrm{~min}$. at $0^{\circ}$.

\begin{tabular}{lc}
\multicolumn{1}{c}{ Additions } & $\begin{array}{c}\text { Inorganic P } \\
\text { liberated } \\
(\mu \text { moles })\end{array}$ \\
Nil & $3 \cdot 2$ \\
Chlorpromazine $(0.2 \mathrm{~mm})$ & $1 \cdot 0$ \\
2:4-Dinitrophenol $(0 \cdot 03 \mathrm{~mm})$ & $3 \cdot 3$ \\
2:4-Dinitrophenol $(0.5 \mathrm{~mm})$ & $4 \cdot 8$ \\
Chlorpromazine $(0.2 \mathrm{mM})$ & $1 \cdot 6$ \\
+ 2:4-dinitrophenol $(0.5 \mathrm{~mm})$ & \\
\hline
\end{tabular}

effect of 2:4-dinitrophenol was considerably decreased when chlorpromazine was present (see Table 1), which shows that the rate of breakdown of ATP in the presence of both chlorpromazine and 2:4-dinitrophenol was little higher than in the presence of chlorpromazine alone.

Since we had shown that suspension of mitoehondria in water profoundly affected the action of chlorpromazine on reduced diphosphopyridine nucleotide (DPNH)-cytochrome $c$ reductase (Dawkins et al. 1959b), we next examined the effect of chlorpromazine on ATP breakdown by watertreated mitochondria. Table 2 shows that the rapid breakdown of ATP by these mitochondrial preparations is powerfully inhibited by chlorpromazine. As might be expected, 2:4-dinitrophenol at $0.03 \mathrm{~mm}$ has no effect on ATP breakdown under these conditions, but 2:4-dinitrophenol at $0.5 \mathrm{~mm}$ accelerates hydrolysis. Chlorpromazine virtually abolishes this effect. Neither chlorpromazine nor 2:4-dinitrophenol was found to have any effect on the adenosine triphosphatase of microsomes at these concentrations.

Adenosine triphosphatase of submitochondrial preparations. The effects of both chlorpromazine and 2:4-dinitrophenol on ATP breakdown by fragments of mitochondria were examined in an attempt to separate the component reactions of ATP breakdown. The preparation obtained by the method of Kielly \& Kielly (1953) is essentially a small-particle 
or submitochondrial system of considerable complexity, which hydrolyses the terminal phosphate of ATP very rapidly. Little or no myokinase activity can be detected in the preparation. The effects of chlorpromazine and 2:4-dinitrophenol are

Table 3. Effect of chlorpromazine and 2:4-dinitrophenol on adenosine triphosphatase of disintegrated mitochondrial preparations (Kielley \& Kielley, 1953)

The components of the system were as described in Table 1. The enzyme was added in $0.1 \mathrm{ml}$. of water, equivalent to $0.2 \mathrm{mg}$. of $\mathrm{N}$, and the time of incubation was $10 \mathrm{~min}$.

\section{Additions}

Nil
Chlorpromazine $(0 \cdot 2 \mathrm{~mm})$
2:4-Dinitrophenol $(0 \cdot 03 \mathrm{mM})$
2:4-Dinitrophenol $(0 \cdot 1 \mathrm{~mm})$
2:4-Dinitrophenol $(1 \cdot 0 \mathrm{~mm})$
Chlorpromazine $(0 \cdot 2 \mathrm{~mm})$
$+2: 4$-dinitrophenol $(0 \cdot 1 \mathrm{~mm})$
Chlorpromazine $(0 \cdot 2 \mathrm{mM})$
$+2: 4$-dinitrophenol $(1 \cdot 0 \mathrm{~mm})$

Inorganic $\mathbf{P}$ liberated ( $\mu$ moles)

$1 \cdot 1$

$0 \cdot 2$

$1 \cdot 3$

$2 \cdot 1$

$2 \cdot 2$

$0 \cdot 3$

$0 \cdot 3$

Table 4. Adenosine triphosphatase of particles obtained by sonic disintegration of mitochondria (SR preparation)

The components of the system were as described in Table 1. Particles (1.5 mg. dry wt.) were added in $0.1 \mathrm{ml}$. of water. Results are corrected for the small amount of inorganic orthophosphate present in the enzyme preparation. Temperature was $20^{\circ}$ and time of incubation $15 \mathrm{~min}$.

$\begin{array}{lc}\quad \text { Additions } & \begin{array}{c}\text { Inorganic P } \\ \text { liberated } \\ (\mu \text { moles })\end{array} \\ \mathrm{Nil} & 6 \cdot 8 \\ \mathrm{Nil} ; \mathrm{Mg}^{2+} \text { ions absent } & 0 \cdot 5 \\ 2: 4-\text { Dinitrophenol }(0.5 \mathrm{mM}) & 7 \cdot 4 \\ \text { Chlorpromazine }(0 \cdot 2 \mathrm{mM}) & 0 \cdot 8\end{array}$

Table 5. Adenosine-triphosphatase activity of SS preparation from mitochondria

The components of the system were as described in Table 1. Preparation SS (dry wt. $4.5 \mathrm{mg}$.) was added in $0.2 \mathrm{ml}$. of water. The temperature was $20^{\circ}$ and time of incubation $30 \mathrm{~min}$. The figures are corrected for the small amount of inorganic phosphate present in the enzyme preparation. The enzyme used in the two experiments was prepared on separate occasions.

\begin{tabular}{clc}
$\begin{array}{c}\text { Expt. } \\
\text { no. }\end{array}$ & \multicolumn{1}{c}{ Additions } & $\begin{array}{c}\text { Inorganic P } \\
\text { liberated } \\
(\mu \text { moles })\end{array}$ \\
1 & Nil & $2 \cdot 2$ \\
& 2:4-Dinitrophenol $(0 \cdot 5 \mathrm{~mm})$ & $4 \cdot 1$ \\
& Nil; $\mathrm{Mg}^{2+}$ ions absent & Nil \\
2 & Nil & $3 \cdot 3$ \\
& Chlorpromazine $(0 \cdot 2 \mathrm{mM})$ & $0 \cdot 5$ \\
& 2:4-Dinitrophenol $(0.5 \mathrm{~mm})$ & $5 \cdot 0$
\end{tabular}

shown in Table 3 , and it can be seen that chlorpromazine inhibits ATP breakdown by some $80 \%$. 2:4-Dinitrophenol at $0.03 \mathrm{~mm}$ has little effect, but at $0.1 \mathrm{~mm}$ and at $1.0 \mathrm{~mm}$ it nearly doubles the rate of breakdown. As with whole mitochondria, chlorpromazine abolishes this effect. These particles have repeatedly failed to show any coupled phosphorylation, though they will oxidize succinate; nor will they catalyse any exchange reaction between ${ }^{32} \mathrm{P}$ and ATP.

Alternative mitochondrial extracts were prepared by sonic disintegration as described in the Methods section. Table 4 shows that the SR preparation contained a powerful adenosine triphosphatase, activated by $\mathbf{M g}^{2+}$ ions, inhibited by chlorpromazine at $\mathbf{0 . 2} \mathrm{mm}$ and only slightly affected by 2:4-dinitrophenol at $0.5 \mathrm{~mm}$. The adenosinetriphosphatase activity of these particles declined by $50 \%$ on overnight storage at $0^{\circ}$; if they were frozen in suspension the activity did not decline, but repeated freezing and thawing destroyed it.

The supernatant fluid (SS preparation) after sonic disintegration was also tested and found to have adenosine-triphosphatase activity. Compared with that of the SR preparation activity was low, being about $5 \%$ on a dry-weight basis. Table 5 shows that it was inhibited $80 \%$ by chlorpromazine, and stimulated $50 \%$ or more by $2: 4$-dinitrophenol. In the absence of $\mathrm{Mg}^{2+}$ ions no activity was detectable.

The SS preparation shared the properties of the SR preparation in that storage at $0^{\circ}$ caused marked loss of activity, as did repeated freezing and thawing. It could be stored frozen at $-10^{\circ}$ for some weeks without loss of activity. The preparation was also tested for cytochrome-oxidase activity, which was present, the $Q_{\mathrm{o}_{2}}$ being $56 \mu \mathrm{l}$. of $\mathrm{O}_{2} / \mathrm{mg}$. dry wt./hr., which is only $2.5 \%$ of the activity of the whole mitochondria. The comparable percentage for the adenosine triphosphatase is $4 \%$. Thus the adenosine-triphosphatase activity of the SS preparation cannot be dissociated from the electrontransport chain. In view of these findings it is likely that the adenosine triphosphatases of the SS and SR preparations are identical.

Action of guanidine and azide on adenosine triphosphatase of SS preparation. Hollunger (1955) demonstrated that the inhibitory effect of guanidine on mitochondrial respiration could be reversed by addition of 2:4-dinitrophenol. This suggested the use of guanidine in our system. The action of azide was also tested, for azide is well known to be an uncoupler of oxidative phosphorylation and an inhibitor of adenosine triphosphatase. In Table 6 are shown the effects of azide, guanidine and chlorpromazine on the adenosine triphosphatase of the SS preparation. Similar results can be obtained with the SR preparation. It will be seen 
Table 6. Effect of 2:4-dinitrophenol on inhibition of adenosine triphosphatase

by azide, guanidine and chlorpromazine

The components of the system were as described in Table 1. Enzyme (dry wt. 4.5 mg.) was added in $0.2 \mathrm{ml}$. of water; temperature was $20^{\circ}$ and time of incubation $30 \mathrm{~min}$.

Concn. of 2:4-dinitrophenol (mM)

\begin{tabular}{|c|c|c|c|c|}
\hline \multicolumn{5}{|c|}{ Inorganic P liberated ( $\mu$ moles) } \\
\hline $2 \cdot 3$ & $3 \cdot 6$ & $3 \cdot 6$ & $3 \cdot 5$ & $3 \cdot 6$ \\
\hline $1 \cdot 3$ & $2 \cdot 4$ & $\mathbf{3} \cdot 6$ & $3 \cdot 6$ & $\mathbf{3 \cdot 6}$ \\
\hline $0 \cdot 75$ & $2 \cdot 0$ & $2 \cdot 2$ & $2 \cdot 6$ & $2 \cdot 8$ \\
\hline $0 \cdot 35$ & 0.5 & 0.5 & $0 \cdot 6$ & $0 \cdot 6$ \\
\hline $0 \cdot 8$ & $1 \cdot 0$ & $1 \cdot 0$ & $1 \cdot 1$ & 0.9 \\
\hline
\end{tabular}

Table 7. Adenosine triphosphate-adenosine diphosphate exchange reaction catalysed by $S R$ preparation

The components of the system were: ATP $5 \mathrm{~mm}$; [ $\left.{ }^{32} \mathrm{P}\right]$ ADP $1.25 \mathrm{~mm}$, with an activity of 2800 counts/min., corrected for background and for residual amounts of [ $\left.{ }^{32} \mathrm{P}\right]$ ATP; 2-amino-2-hydroxymethylpropane-1:3-diol-HCl buffer, pH 7.2, $50 \mathrm{~mm}$; particles (dry wt. $1.5 \mathrm{mg}$.) in $0.1 \mathrm{ml}$. of water. Final volume was $2 \mathrm{ml}$., temperature $20^{\circ}$ and incubation time $30 \mathrm{~min}$.

\section{Additions}

Nil

$\mathrm{MgSO}_{4}(5 \mathrm{~mm})$

Azide (1 mM)

Azide (1 mM) $+\mathrm{MgSO}_{4}(5 \mathrm{~mm})$ of ATP breakdown, the action of which is not reversed by increasing concentrations of 2:4dinitrophenol.

Effect of azide, chlorpromazine, guanidine and 2:4-dinitrophenol on the adenosine triphosphateadenosine diphosphate-exchange reaction. Wadkins \& Lehninger (1958) have shown that submitochondrial particles prepared by treating whole mitochondria with $1 \%$ digitonin will catalyse an exchange between unlabelled ATP and [ $\left.{ }^{32} \mathrm{P}\right] \mathrm{ADP}$, and that this reaction becomes insensitive to 2:4dinitrophenol on storage. Azide increased the amount of exchange in the fresh particles, presumably because it inhibits ATP breakdown. This exchange reaction is thought to be the terminal reaction of oxidative phosphorylation. An acetone-dried powder prepared from these digitonin particles also catalysed ATP-ADP exchange and had no adenosine-triphosphatase activity. The SR preparation was therefore tested to find whether ATP-ADP exchange could occur. Table 7 shows that exchange does occur and shows the effect of azide and $\mathrm{Mg}^{2+}$ ions upon it. Direct observation failed to show any myokinase activity. It will be seen that exchange is greatly enhanced by $\mathrm{Mg}^{2+}$ ions and by azide, and that it is greatest when both are present. $\mathrm{Mg}^{2+}$ ions have two actions in this system, since they are required for the ATP-ADP exchange but at the same time will also activate adenosine triphosphatase. Azide presumably stimulates activity by inhibiting the adenosine triphosphatase of the fresh particles. In order to remove adenosine-triphosphatase activity an acetone-dried powder was prepared from the freshly isolated particles. Table 8 shows the results of an experiment with this material. A rapid exchange is catalysed by the preparation; there is virtually no formation of labelled ATP when ATP is omitted, which indicates that no myokinase activity is present. Chlorpromazine and 2:4-dinitrophenol do not inhibit this reaction, and indeed produce some slight increase in the counts found in ATP. Guanidine was also without effect. that guanidine at $0.01 \mathrm{M}$ and $0.02 \mathrm{M}$ powerfully inhibits adenosine triphosphatase, and that this action is reversed by increasing concentrations of 2:4-dinitrophenol. In contrast, the inhibition by chlorpromazine is scarcely affected by 2:4-dinitrophenol, which agrees with our previous findings on the effect of chlorpromazine and 2:4-dinitrophenol on respiration of whole mitochondria (Dawkins et al. 1959b). Azide is also an inhibitor

\section{Guanidine was also without effect.}


The acetone-dried powder was also tested for adenosine-triphosphatase activity and exchange of inorganic phosphate into ATP; no activity was found in either case.

Position of phosphate label. After the ATPADP-exchange reaction had taken place, the solutions were boiled and then incubated with hexokinase and glucose for $1 \mathrm{hr}$. at $38^{\circ}$. Trichloroacetic acid to a final concentration of $5 \%$ was added, the small protein precipitate removed and the tubes were adjusted to $\mathrm{pH} 4$ with sodium acetate. The solution was then treated twice with charcoal to remove nucleotides (Crane \& Lipmann, 1953). The glucose 6-phosphate remaining in solution was counted and found to contain only $6 \%$ of the radioactivity. This means that there is no redistribution of the pyrophosphate groups of ATP during the reaction and that there can be no myokinase activity. ADP must be phosphorylated by the ATP present to give a radioactive ATP labelled solely in the $\beta$-phosphate group.

Attempts to reconstitute adenosine triphosphatase. Since the acetone-dried powder has no adenosinetriphosphatase activity by itself, theoretically it should be possible to obtain another fraction containing the further enzymes involved in the hydrolysis of ATP, which, in combination with the acetone-dried powder, would hydrolyse ATP. Fractionation of both SR and SS preparations with ammonium sulphate and ethanol, and decreasing the pH to 4, did not yield any such fraction.

\section{DISCUSSION}

It can be seen from these results that chlorpromazine is an inhibitor of the mitochondrial magnesium-activated adenosine triphosphatase in preparations in which breakdown is maximal. It blocks the increase in activity produced by $2: 4$ dinitrophenol and reduces the adenosine-triphosphatase activity of disintegrated and submitochondrial preparations. However, chlorpromazine has little effect on the very low adenosine-triphosphatase activity of fresh mitochondria in $0.25 \mathrm{M}$ sucrose. Mitochondrial adenosine triphosphatase is firmly associated with the insoluble particlebound enzymes of the respiratory chain. Wadkins \& Lehninger (1959) have shown that the state of reduction of the chain has a profound effect on adenosine-triphosphatase activity, which is maximal when the chain is fully oxidized. If adenosinetriphosphatase activity is indeed a reversal of some of the terminal steps in the oxidative-phosphorylation sequence, then it appears that chlorpromazine is acting by blocking some reaction before the site of action of 2:4-dinitrophenol.

However, in our previous work (Dawkins, Judah $\&$ Rees, 1958, 1959b) we have shown that chlor- promazine blocks the stimulating action of 2:4dinitrophenol in preparations whose respiration is limited by deficiency of ADP and inorganic phosphate, apparently by blocking some reaction before the 2:4-dinitrophenol-stimulated hydrolysis of some phosphorylated intermediate. These findings may be interpreted to mean either two sites of action for chlorpromazine, or that the same locus is involved in both circumstances.

The breakdown of ATP can be formulated thus:

$$
\begin{gathered}
\mathrm{ATP}+\mathrm{E}_{\mathrm{x}} \rightleftharpoons \mathrm{ADP}+\mathrm{E}_{\mathrm{x}} \sim \mathrm{P} \\
\mathrm{E}_{\mathrm{x}} \sim \mathrm{P}+\mathrm{B} \rightleftharpoons \mathrm{B} \sim \mathrm{P}+\mathrm{E}_{\mathrm{x}} \\
\mathrm{B} \sim \mathrm{P} \rightarrow \mathrm{B}+\mathrm{iP}
\end{gathered}
$$

where reaction (1) is the ATP-ADP-exchange reaction as described by Lehninger (1958), reaction (2) is the transfer of phosphate to a hypothetical intermediate B (probably an electron carrier; see below) and reaction (3) is that stimulated by $2: 4$ dinitrophenol. iP is inorganic phosphate and $\mathrm{E}_{\mathrm{x}}$ is a hypothetical phosphotransferase. Reactions (1) and (2) are part of the oxidative-phosphorylation sequence but reaction (3) is not. We postulate that chlorpromazine inhibits reaction (3). However, it is apparent that chlorpromazine also inhibits reaction (2) since it inhibits electron transport between DPNH and cytochrome $c$ in phosphorylating systems, without altering the efficiency of the coupled phosphorylation (Dawkins et al. 1959b). Azide has been shown by Lehninger (1958) to prevent the inhibitory action of 2:4-dinitrophenol on the ATP-ADP exchange in fresh submitochondrial particles prepared by treatment with digitonin. When these particles are stored the ATPADP exchange is no longer sensitive to 2:4-dinitrophenol. Azide also inhibits 2:4-dinitrophenolstimulated adenosine triphosphatase. Therefore azide must inhibit reaction (2) in the scheme for ATP breakdown. However, azide differs from chlorpromazine in being an uncoupler of oxidative phosphorylation, and therefore can have no inhibitory effect on reaction (3), since it must allow the hydrolysis of a phosphorylated intermediate. Guanidine must have a similar site of action to chlorpromazine. However, it differs from chlorpromazine in that the inhibitory effect, both on respiration and adenosine triphosphatase, can be reversed by increasing the concentration of 2:4dinitrophenol. Increasing concentrations of 2:4dinitrophenol do not affect the inhibitions caused by chlorpromazine and azide.

The inhibition of respiration by chlorpromazine of the span DPNH-cytochrome $c$ in phosphorylating systems (Dawkins et al. 1959b), the inhibitory effect of chlorpromazine on ${ }^{32} \mathrm{P}-\mathrm{ATP}$ exchange (Dawkins et al. 1958) and the effect on adenosine triphosphatase described in this paper all suggest 
an action on $\mathbf{a}$ phosphorylated intermediate. Wadkins \& Lehninger (1959) have reported that ${ }^{32} \mathrm{P}-\mathrm{ATP}$ exchange and adenosine triphosphatase are maximal when the electron-transport chain is fully oxidized, suggesting a very close association between the incorporation of inorganic phosphate and the electron chain. These findings may be explained if there is direct phosphorylation of the flavoprotein electron carrier, as originally suggested by Lipmann (1946). This suggestion has largely been discounted because the rate of respiration of the Keilin-Hartree preparation is independent of phosphate concentration (Slater, 1953). More recently Lindberg, Grabe, Löw, Siekevitz \& Ernster (1958) have suggested direct phosphorylation of the flavoprotein electron carrier, and have supported this by indirect evidence (see Löw, Siekevitz, Ernster \& Lindberg, 1958). We are in agreement with the recent suggestion of Löw (1959) that the phosphorylated flavoprotein is implicated as the site of action of 2:4-dinitrophenol, and that chlorpromazine acts by combination with flavoprotein. However, the associated formulation for the oxidative-phosphorylation reaction (Lindberg et al. 1958) suggests direct transphosphorylation of ADP by phosphorylated flavoprotein. This does not allow for the ATP-ADP-exchange reaction described by Lehninger (1958).

To allow for these findings the sequence of oxidative-phosphorylation reactions may then be written:

$$
\begin{gathered}
\mathrm{AH}_{2}+\mathrm{B} \rightarrow \mathrm{BH}_{2}+\mathrm{A} \\
\mathrm{BH}_{2}+\mathrm{iP}+\mathrm{Cyt}_{\text {ox. }} \rightarrow \mathrm{Cyt}_{\text {red. }}+\mathrm{B} \sim \mathrm{P} \\
\mathrm{B} \sim \mathrm{P}+\mathrm{E}_{\mathrm{x}} \rightarrow \mathrm{E}_{\mathbf{x}} \sim \mathrm{P}+\mathrm{B} \\
(\mathrm{B} \sim \mathrm{P} \rightarrow \mathrm{B}+\mathrm{iP}) \\
\mathrm{E}_{\mathrm{x}} \sim \mathrm{P}+\mathrm{ADP} \rightarrow \mathrm{ATP}+\mathrm{E}_{\mathrm{x}}
\end{gathered}
$$

where $\mathrm{AH}_{2}$ is DPNH, $\mathrm{B}$ is the flavoprotein DPNHcytochrome reductase and Cyt is the cytochrome system. We postulate that chlorpromazine acts by inhibiting both the reactions of $B \sim P$, either hydrolysis under the influence of 2:4-dinitrophenol or transphosphorylation to $\mathrm{F}_{\mathrm{x}}$. Dawinins, Judah \& Rees $(1959 c)$ have shown that several phenothiazines including chlorpromazine inhibit the microsomal DPNH-cytochronie \& roductase. Recently Yagi, Ozawa \& Nagatsu (1959) have shown that chlorpromazine combines in vitro to form a complex with flavinadenine dinucleotide. It seems probable therefore that chlorpromazine acts by combining directly with the flavine part of DPNH-cytochrome $c$ reductase, and in so doing blocks the hydrolysis or phosphate transfer of the phosphorylated flavoprotein. In this context it is of interest that Löw was able to reverse the inhibitory effect of chlorpromazine on adenosine triphosphatase by the addition of flavinadenine dinucleotide.

\section{SUMMARY}

1. Chlorpromazine inhibits the 2:4-dinitrophenolstimulated adenosine triphosphatase of mitochondria in $0.25 \mathrm{M}$-sucrose and the magnesiumactivated adenosine triphosphatase of sub-mitochondrial preparations.

2. Guanidine and azide have similar effects.

3. Guanidine, azide and chlorpromazine do not affect the adenosine triphosphate-adenosine diphosphate-exchange reaction.

4. On the basis of these observations and previous results, formulations for the action of adenosine triphosphatase and the oxidative-phosphorylation sequence are presented.

We are grateful to Sir Roy Cameron, F.R.S., for his interest and encouragement. The expenses of the investigation were met from the Graham Research Fund of the University of London.

\section{REFERENCES}

Cooper, C. \& Lehninger, A. L. (1957). J. biol. Chem. 224, 561.

Crane, R. K. \& Lipmann, F. (1953). J. biol. Chem. 201, 235.

Dawkins, M. J. R., Judah, J. D. \& Rees, K. R. (1958). Nature, Lond., 182, 875.

Dawkins, M. J. R., Judah, J. D. \& Rees, K. R. (1959a). Biochem. J. 72, 204.

Dawkins, M. J. R., Judah, J. D. \& Rees, K. R. (1959b). Biochem. J. 73, 16.

Dawkins, M. J. R., Judah, J. D. \& Rees, K. R. (1959c). Biochem. Pharmacol. 2, 112.

Fiske, F. H. \& Subbarow, Y. (1925). J. biol. Chem. 66, 375. Hollunger, G. (1955). Acta. pharm. tox., Kb., Suppl. no. 1. Kennedy, E. P. (1953). J. biol. Chem. 201, 399.

Kielly, W. W. \& Kielly, R. K. (1953). J. biol. Chem. 200, 213.

Lardy, H. A. \& Wellman, H. (1953). J.biol. Chem. 201, 357.

Lehninger, A. L. (1958). Science, 128, 450.

Lindberg, O., Grabe, B., Löw, H., Siekevitz, P. \& Ernster, L. (1958). Acta chem. scand. 12, 598.

Lipmann, F. (1946). Currents in Biochemical Research, p. 137. New York: Interscience Publishers Inc.

Löw, H. (1959). Biochim. biophys. Acta, 32, 11.

Löw, H., Siekevitz, P., Ernster, L. \& Lindberg, O. (1958). Biochim. biophys. Acta, 29, 392.

Schneider, W. C. (1948). J. biol. Chem. 176, 259.

Siekevitz, P., Löw, H., Ernster, L. \& Lindberg, O. (1958). Biochim. biophys. Acta, 29, 378.

Slater, E. C. (1953). Nature, Lond., 172, 975.

Wadkins, C. L. \& Lehninger, A. L. (1958). J. biol. Chem. 233, 1589.

Wadkins, C. L. \& Lehninger, A. L. (1959). J. biol. Chem. 234, 681.

Yagi, K., Ozawa, T. \& Nagatsu, T. (1959). Nature, Lond., 184, 982. 